\title{
Molecular Modeling of Heat Shock Protein of 60-Kda from Paracoccidioides Brasiliensis: The First in silico Structural Model of a Fungal Hsp60
}

\author{
Fabrício Freitas Fernandes ${ }^{1}$, Renata Ariza Marques Rossetti ${ }^{2}$, Arlete Coelho-Castelo ${ }^{3}$ and Ademilson Panunto-Castelo ${ }^{4 *}$ \\ ${ }^{1}$ Department of Cell and Molecular Biology and Pathogenic Bioagents, Ribeirão Preto Medical School, University of São Paulo, São Paulo, Brazil \\ ${ }^{2}$ Department of Immunology, Institute of Biomedical Sciences, University of São Paulo, São Paulo, Brazil \\ ${ }^{3}$ Department of Biochemistry and Immunology, Ribeirão Preto Medical School, University of São Paulo, São Paulo, Brazil \\ ${ }^{4}$ Department of Biology, College of Philosophy, Sciences and Literature of Ribeirão Preto, University of São Paulo, São Paulo, Brazil
}

\begin{abstract}
Paracoccidioides brasiliensis is a dimorphic fungus that causes paracoccidioido mycosis (PCM), an endemic mycosis in Latin America. PCM is a chronic, granulomatous, and progressive disease, which has a wide clinical spectrum of manifestations. Although it knows that the main clinical forms are consequences of fungus-host interaction, immune response in PCM is still an open field. The antigenic complexity of $P$. brasiliensis and the role of most antigens have been poorly explored, thereby decreasing the chances of finding vaccine and therapeutic targets for PCM. Recent results from our group have shown that heat shock protein of $60-\mathrm{kDa}$ from $P$. brasiliensis strain 18 (Hsp60_Pb18) has a possible detrimental effect on the course of the PCM. Here, we show the molecular model of $\mathrm{Hsp60} \mathrm{Pb} 18$ that was generated with the program MODELLER9V8. The model validation was performed using PROCHECK and VERIFY3D. According to the results, the three-dimensional structure of Hsp60_Pb18 is a high reliability model, which displays a remarkable similarity with the three distinct domains of GroEL subunit-equatorial, intermediate and apical domains. This study will provide direction and continuity of studies to characterize Hsp60 $\mathrm{Pb} 18$ and their domains, and thus contribute to the knowledge of the fungus biology and to determine vaccines and/ or therapeutic targets.
\end{abstract}

Keywords: Paracoccidioides brasiliensis; Vaccines target; Heat shock protein; Modeller, 3D structure

\section{Introduction}

Paracoccidioidomycosis (PCM) is a systemic mycosis of chronic granulomatous nature caused by the fungus Paracoccidioides brasiliensis [1]. This is the most prevalent systemic mycosis in Latin America with about 10 million of infected people, of which 1 to $2 \%$ will develop the disease manifestations. Although Brazil, Argentina, Colombia and Venezuela are responsible for almost all cases, Brazil contains the largest number of endemic areas, representing $80 \%$ of all reported cases of PCM in Latin America [2].

The infection with $P$. brasiliensis is initiated when the host inhales fragments or conidia from mycelium, which is the form of the $P$. brasiliensis at environmental temperature. Because of the host temperature, 35 to $37^{\circ} \mathrm{C}$, primarily in the lungs, the mycelial form is converted to yeasts, which are the resistance form of the fungus [1]. $P$. brasiliensis infection can be restricted to the lungs or disseminated to other organs, leading to a wide spectrum of manifestations, i.e. the infection can range from asymptomatic to severe disseminated forms. PCM can be classified in two main clinical forms, acute/subacute and chronic ones. The acute/subacute disease has a rapid onset and affects the mononuclear phagocyte system of young people from both genders. The most common form of PCM is the chronic one, which has a slow evolution, involves lesions in few organs and mucosa mainly in adult men [3]. Some disseminated forms are associated with a less efficient immune response, a worse prognosis and more frequent relapses of the disease, as occurs in acute and subacute and chronic severe forms [4].

The antigenic complexity of $P$. brasiliensis has been little explored in terms of isolation and identification of new antigens and, consequently, elucidation of the role these molecules play in PCM. Our group has worked with identification of $P$. brasiliensis antigens [5] and studied the action of adjuvants or antigens in order to find important molecules for the development of immunotherapy for the PCM [6-9]. More recently, we identified heat shock protein of $60-\mathrm{kDa}$ (Hsp60) from fungal fractions as a component that worsens the experimental PCM. Despite the Hsp60 presents a protective effect against PCM when administered prophylactically [10], our results show that this protein leads to a more severe experimental PCM with increased fungal burden and tissue injury when therapeutically administered (unpublished data). Therefore, this issue is of fundamental importance for the design of new vaccines and treatment, as well as to understand the biology of the fungus. Among potential vaccine candidates for infection diseases or cancer are the heat-shock proteins (Hsp), since they are associated with different phenomena of innate and adaptive immunity $[11,12]$. Initially, Hsp were seen as ubiquitous molecules produced by organisms or cells in response to exposure to elevated temperatures. In fact, Hsp are molecules involved in functions as molecular chaperones and co-chaperones by binding to intracellular and misfolded proteins, preventing the aggregation of these molecules and promoting their proper refolding and transport $[13,14]$. They are grouped in families based on their sequence homology and molecular weight, such as human Hsp110, Hsp90, Hsp70, Hsp60, Hsp40 and small Hsp [15].

*Corresponding author: Ademilson Panunto-Castelo, Department of Biology College of Philosophy, Sciences and Literature of Ribeirão Preto, University of São Paulo, São Paulo, Brazil, Tel: 55-16-3206-0454; E-mail: apcastelo@usp.br

Received October 10, 2014; Accepted November 04, 2014; Published January 03, 2015

Citation: Fernandes FF, Rossetti RAM, Coelho-Castelo A, Panunto-Castelo A (2014) Molecular Modeling of Heat Shock Protein of 60-Kda from Paracoccidioides Brasiliensis: The First in silico Structural Model of a Fungal Hsp60. J Comput Sci Syst Biol 8: 241-244. doi:10.4172/jcsb.1000164

Copyright: (C) 2014 Fernandes FF. This is an open-access article distributed unde the terms of the Creative Commons Attribution License, which permits unrestricted use, distribution, and reproduction in any medium, provided the original author and source are credited. 
Citation: Fernandes FF, Rossetti RAM, Coelho-Castelo A, Panunto-Castelo A (2014) Molecular Modeling of Heat Shock Protein of 60-Kda from Paracoccidioides Brasiliensis: The First in silico Structural Model of a Fungal Hsp60. J Comput Sci Syst Biol 8: 241-244. doi:10.4172/ jcsb.1000164

Hsp60 is a molecular chaperone known to assist protein folding in prokaryotes and in eukaryotic cell organelles [16].In eukaryotes, Hsp60 typically resides in the organelles mitochondria and chloroplasts but it also occurs in the cytosol [17], mammalian cell surface [18], fungal cell wall [19] and extracellular space [20]. Extracellular Hsp60 can interact with a number of cell-surface receptors, such as CD14, CD40 and Tolllike-receptors (TLRs) [21], and induce pro- and anti-inflammatory effects [22].

Fungal Hsp60 has been identified acting as immunodominant antigens, resulting in humoral and cellular responses, including an induction of regulatory $\mathrm{T}$ cells through interaction with cells of the innate immune system [23,24]. Moreover, Raggam et al. [25] have shown that Hsp60 mRNA could be induced in eight fungal species under stress conditions and suggested that fungal Hsp60 might play a key coordinating role in the immune response of fungi-associated diseases.

Recent results from our group have shown that Hsp60 from $P$. brasiliensis has a potential detrimental effect on the course of PCM (unpublished data), probably because Hsp60 can modulate immune response by stimulating $\mathrm{T}$ regulatory cells [26], as well as other immune system components [27].

Bioinformatics tools have been applied to the identification of new molecular structures, relating them to their possible functions and thus directing future studies more objectively. In this study, we show the predicted three-dimensional heat shock protein of $60-\mathrm{kDa}$ from $P$. brasiliensis strain 18 (Hsp60_Pb18) performed by molecular modeling and in silico evaluation of this proposed structure. According to these results, the Hsp60 model is highly reliable.

\section{Methods}

\section{Sequence retrieval and alignment}

The sequence of the Hsp60_Pb18 (PADG_08369) from $P$. brasiliensis was retrieved from the Broad Institute, in a FASTA format (http://www.broadinstitute.org/annotation/genome/paracoccidioides_ brasiliensis/TranscriptDetails.html?sp=S7000001960871783). Search for similar proteins with determined three-dimensional structures was done in the Protein Data Bank (http://www.rcsb.org/pdb/home/home. do). After obtaining the similar protein, the alignment was made using the software ClustalW2 (http://www.ebi.ac.uk/Tools/msa/clustalw2/).

\section{Model building and evaluation}

The MODELLER9V8 [28] was used to predict the three-dimensional structure of the protein. The obtained model was stereochemically validated by PROCHECK [29] and VERIFY3D [30]. The PROCHECK checked if the spatial properties were right, such as peptide bond planarity, nonbonded interactions, main chain hydrogen bond energy, and others. The VERIFY3D validated the refined model by analyzing the compatibility of an atomic model (3 Dimensional) with its own amino acid sequence (1 Dimensional), throughout a validated known score matrix built based on structures from the Protein Data Bank (PDB).

\section{Results and Discussion}

The complete protein sequence of Hsp60_Pb18 (PADG_08369.1) was used in the study. The length of Hsp60_Pb18 is 595 amino acids, with expected molecular weight of $62,389.21 \mathrm{Da}$ and isoelectric point (pI) of 5.51. Figure 1 shows the amino acid sequence of the Hsp60_Pb18 with the conserved chaperones domain Cpn60/TCP1. Proteins with
MQRAFTSSRALVLSSASSASSTRAPLSRFRSAGVGLQQQRFAHKELKFGVEARASLLKGIDT LAKAVTTTLGPKGRNVLIESPYGSPKITKDGVTVAKAVNLQDKFENLGARLIQDVASKTNEV AGDGTTTATVLARAIFSETVKNVAAGCNPMDIRRGIOSAVEAVVEYLOANKRDITTTEFIAO VATISANGDTHVGKLISNAMEKVGKEGVITVKDGKTIDDELEVTEGMRFDRGYVSPYFITDT KAQKVEFEKPLI LLSEKKISAVQDI I PALEASTSLRRPLVI IAEDIEGEALAVCILNKLRGQ LQVAAVKAPGFGDNRKSILGDIGILTNATVFTDELDLKLEKATPDMLGSTGSITITKEDTI I LNGEGSKDAIAORCEQIRSVISDPATSDYEKEKLQERLAKLSGGVAVIKVGGASEIEVGEKK DRVVDALNATRAAVEFGIL PGGTTALIKAAANGITSLNPTNFDOKLGISI IKNAITRPARTI VENSGLEGSVIVGKLTDDFASDFNRGFDSAKGEYVDMIGAGIVDPLKVVRTALVDASGVASI LGTTEVAIVEAPEEKVPAGSGAGGMGGGMGGMGGGMF

Figure 1: Amino acid sequence of the Hsp60_Pb18 protein obtained from the Broad Institute. The chaperone protein domain Cpn60/TCP1 is marked in blue.

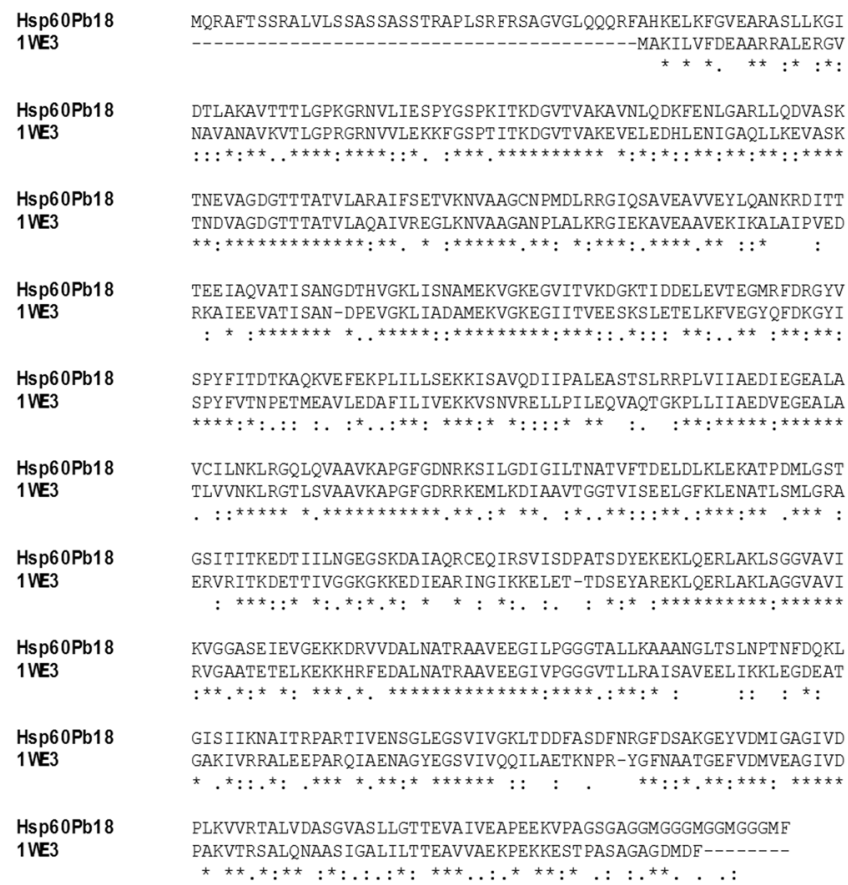

Figure 2: Amino acid sequence alignment of Hsp60_Pb18 protein with the 1WE3 protein sequence using Clustal W2. The displayed similarity between the sequences was $54 \%$. The signals *, : and . indicate identical amino acids, conservative changes and semiconservative modifications, respectively, occupying the same position in both sequences.

these domains are induced under stress and work on the stabilization and protection of the polypeptides arrangement under conditions of heat shock (NCBI-http://www.ncbi.nlm.nih.gov/Structure/cdd/wrpsb. cgi).

As Hsp60_Pb18 did not have a three-dimensional structure available, we searched for other proteins that shared high amino acid sequence similarity with Hsp60_Pb18 and could be used as a template for protein modeling. We found three possible model proteins (1IOKA, 1KP8A e 1WE3A) by using the BLAST program and confirmed the high percentages of similarities between these sequences by ClustalW2 align software (data not shown). The modeling of protein Hsp60_Pb18 was performed with the three selected sequences, but the generated model was based on 1WE3A protein (54\% similarity) (Figure 2), which provided the best stereochemical results (Figure 3). As expected, the obtained structure is quite similar to best-characterized chaperonin subunit GroEL (cpn60) from Escherichia coli, and comprises of three domains. The largest domain is the equatorial, which is high $a$-helical and well-ordered. The intermediate domain is the smaller and provides 
Citation: Fernandes FF, Rossetti RAM, Coelho-Castelo A, Panunto-Castelo A (2014) Molecular Modeling of Heat Shock Protein of 60-Kda from Paracoccidioides Brasiliensis: The First in silico Structural Model of a Fungal Hsp60. J Comput Sci Syst Biol 8: 241-244. doi:10.4172/ jcsb.1000164

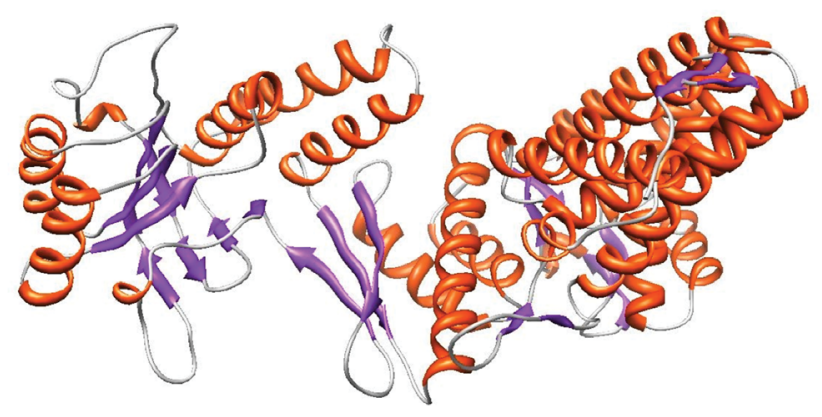

Figure 3: The best model of the 3D structure of the Hsp60 Pb18 protein obtained by Modeller9v2 based on the alignment with 1WE3A protein. In red are the $\alpha$-helices and the $\beta$-sheets are in lilac.

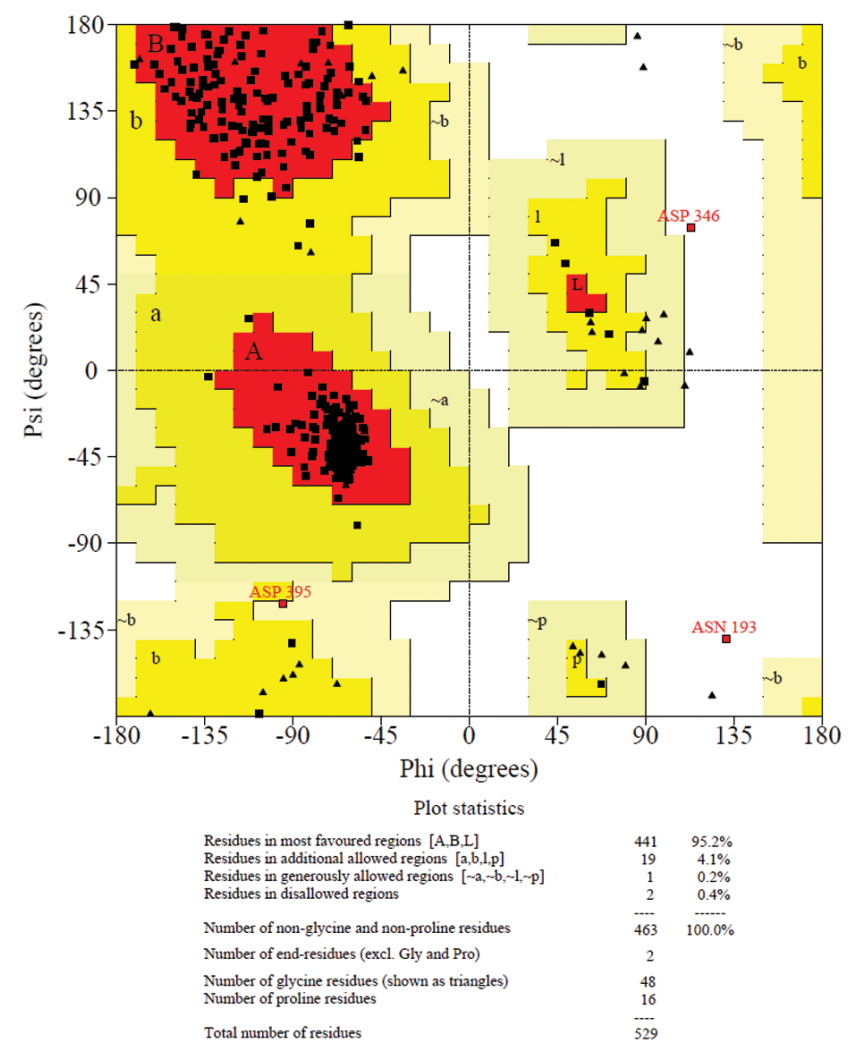

Figure 4: Ramachandran plot of the psi/phi distribution of the Hsp60_Pb18 model as obtained by PROCHECK.

connection between equatorial and apical domains. The apical domain is a mixture of $\alpha$-helices and $\beta$-sheet. Once the modeled structure is quite similar to subunit cpn60 of GroEL family [31], we suggest that the domains of Hsp60_Pb18 have analogous functions, i.e., equatorial domain with ATPase function and apical domain with binding site for non-native proteins and GroES [31].

The level quality of a model generated by structural homology depends on a large number of properties, such as stereochemistry accuracy, quality, packaging and reliability of folding [32]. Thus, the generated model was subject to validation using PROCHECK [29] and VERIFY3D [30]. These two software applications encompass the analysis of the main properties to obtain a good molecular model.
The Ramashandran plot shows that the Hsp60_Pb18 structure has $95.2 \%$ residues in most favorable regions, $4.1 \%$ in additionally allowed regions and only $0.4 \%$ in disallowed regions. To be considered a good model, $90 \%$ of the residues should be located in favorable regions, so the model obtained can be considered a good representation of the $3 \mathrm{D}$ structure of the protein in question (Figure 4). Models with a high degree of reliability may be promising in the search for biologically active compounds as well as in optimizing prototypes, serving as a structural basis for the testing of hypotheses in medicinal chemistry, for example, in planning selective drugs for a particular therapeutic target [33].

The analysis performed by VERIFY3D evaluated the folding reliability, based on a statistical analysis involving the protein structures from the PDB. The results generated by this program showed that all residues are within acceptable range (between 0 and 0.62 ). Thus, it can be stated that the proposed model is consistent with the stereochemical parameters described above.

The three-dimensional structure generated in this work provides a good model for docking studies, mainly between this protein and the receptors of innate immunity cells, which could contribute to the knowledge of stimuli and receptors involved in the modulation of the immune response during PCM. Furthermore, this study will help to the development drugs that interact with important domains of this protein, specifically, and thus inhibiting its activity deleterious to the host.

\section{Conclusion}

According to this study, we can say that the Hsp60_Pb18 threedimensional structure is a reliable model, but it is only predictive, and needs experimental confirmation. Therefore, these results will contribute to the direction and continuity of studies to characterize Hsp60_Pb18 and their domains, collaborating to the knowledge of the fungus biology and to determine vaccines and/or therapeutic targets.

\section{Acknowledgement}

We acknowledge the financial support of the São Paulo Research foundation -FAPESP (Grant numbers 2009/03235-3 and 2009/12278-3) and CNPq.

\section{References}

1. Brummer E, Castaneda E, Restrepo A (1993) Paracoccidioidomycosis: an update. Clin Microbiol Rev 6: 89-117.

2. Colombo AL, Tobón A, Restrepo A, Queiroz-Telles F, Nucci M (2011) Epidemiology of endemic systemic fungal infections in Latin America. Med Mycol 49: 785-798.

3. Franco M, Montenegro MR, Mendes RP, Marques SA, Dillon NL, et al. (1987) Paracoccidioidomycosis: a recently proposed classification of its clinical forms. Rev Soc Bras Med Trop 20: 129-132.

4. Fortes MR, Miot HA, Kurokawa CS, Marques ME, Marques SA (2011) Immunology of paracoccidioidomycosis. An Bras Dermatol 86: 516-524.

5. Panunto-Castelo A, Freitas-da-Silva G, Bragheto IC, Martinez R, RoqueBarreira MC (2003) Paracoccidioides brasiliensis exoantigens: recognition by IgG from patients with different clinical forms of paracoccidioidomycosis. Microbes Infect 5: 1205-1211.

6. Coltri KC, Casabona-Fortunato AS, Gennari-Cardoso ML, Pinzan CF, Ruas LP, et al. (2006) Paracoccin, a GlcNAc-binding lectin from Paracoccidioides brasiliensis, binds to laminin and induces TNF-alpha production by macrophages. Microbes Infect 8: 704-713.

7. Coltri KC, Oliveira LL, Pinzan CF, Vendruscolo PE, Martinez R, et al (2008) Therapeutic administration of $\mathrm{KM}+$ lectin protects mice against Paracoccidioides brasiliensis infection via interleukin-12 production in a toll-like receptor 2-dependent mechanism. Am J Pathol 173: 423-432. 
Citation: Fernandes FF, Rossetti RAM, Coelho-Castelo A, Panunto-Castelo A (2014) Molecular Modeling of Heat Shock Protein of 60-Kda from Paracoccidioides Brasiliensis: The First in silico Structural Model of a Fungal Hsp60. J Comput Sci Syst Biol 8: 241-244. doi:10.4172/ jcsb.1000164

8. Coltri KC, Oliveira LL, Ruas LP, Vendruscolo PE, Goldman MH, et al. (2010) Protection against Paracoccidioides brasiliensis infection conferred by the prophylactic administration of native and recombinant ArtinM. Med Mycol 48: 792-799.

9. de Oliveira LL, Coltri KC, Cardoso CR, Roque-Barreira MC, PanuntoCastelo A (2008) T helper 1-inducing adjuvant protects against experimental paracoccidioidomycosis. PLoS Negl Trop Dis 2: e183.

10. Soares RBA, Gomez FJ, de Almeida Soares CM, Deepe GS Jr. (2008) Vaccination with heat shock protein 60 induces a protective immune response against experimental Paracoccidioides brasiliensis pulmonary infection. Infect Immun 76: 4214-4221.

11. McNulty S, Colaco CA, Blandford LE, Bailey CR, Baschieri S, et al. (2013) Heat-shock proteins as dendritic cell-targeting vaccines--getting warmer. Immunology 139: 407-415.

12. Segal BH, Wang XY, Dennis CG, Youn R, Repasky EA, et al. (2006) Hea shock proteins as vaccine adjuvants in infections and cancer. Drug Discov Today 11: $534-540$.

13. Lindquist S (1986) The heat-shock response. Annu Rev Biochem 55: 1151 1191.

14. Parsell DA, Lindquist S (1993) The function of heat-shock proteins in stress tolerance: degradation and reactivation of damaged proteins. Annu Rev Genet 27: 437-496.

15. Kampinga HH, Hageman J, Vos MJ, Kubota H, Tanguay RM, et al. (2009) Guidelines for the nomenclature of the human heat shock proteins. Cell Stress Chaperones 14: 105-111.

16. Cappello F, Conway de Macario E, Marasà L, Zummo G, Macario AJ (2008) Hsp60 expression, new locations, functions and perspectives for cancer diagnosis and therapy. Cancer Biol Ther 7: 801-809.

17. Naylor DJ, Hartl FU (2001) Contribution of molecular chaperones to protein folding in the cytoplasm of prokaryotic and eukaryotic cells. Biochem Soc Symp: 45-68.

18. Soltys BJ, Gupta RS (1997) Cell surface localization of the $60 \mathrm{kDa}$ heat shock chaperonin protein (hsp60) in mammalian cells. Cell Biol Int 21: 315-320.

19. Holbrook ED, Rappleye CA (2008) Histoplasma capsulatum pathogenesis: making a lifestyle switch. Curr Opin Microbiol 11: 318-324.
20. Gupta S, Knowlton AA (2007) HSP60 trafficking in adult cardiac myocytes: role of the exosomal pathway. Am J Physiol Heart Circ Physiol 292: H3052-3056.

21. Pockley AG, Muthana M, Calderwood SK (2008) The dual immunoregulatory roles of stress proteins. Trends Biochem Sci 33: 71-79.

22. Steinhoff U, Brinkmann V, Klemm U, Aichele $P$, Seiler $P$, et al. (1999) Autoimmune intestinal pathology induced by hsp60-specific CD8 T cells. Immunity 11: 349-358.

23. Habich C, Kempe K, Gomez FJ, Lillicrap M, Gaston H, et al. (2006) Hea shock protein 60: identification of specific epitopes for binding to primary macrophages. FEBS Lett 580: 115-120.

24. van Eden W, Hauet-Broere F, Berlo S, Paul L, van der Zee R, et al. (2005) Stress proteins as inducers and targets of regulatory $T$ cells in arthritis. Int Rev Immunol 24: 181-197.

25. Raggam RB, Salzer HJ, Marth E, Heiling B, Paulitsch AH, et al. (2011) Molecular detection and characterisation of fungal heat shock protein 60 Mycoses 54: e394-399.

26. Zanin-Zhorov A, Cahalon L, Tal G, Margalit R, Lider O, et al. (2006) Heat shock protein 60 enhances CD4+ CD25+ regulatory T cell function via innate TLR2 signaling. J Clin Invest 116: 2022-2032.

27. Quintana FJ, Cohen IR (2011) The HSP60 immune system network. Trends Immunol 32: 89-95

28. Sali A (1995) Comparative protein modeling by satisfaction of spatial restraints Mol Med Today 1: 270-277.

29. Laskowski RA, MacArthur MW, Moss DS, Thornton JM (1993) PROCHECK: A program to check the stereochemical quality of protein structures. J Appl Crys 26: 283-291.

30. Lüthy R, Bowie JU, Eisenberg D (1992) Assessment of protein models with three-dimensional profiles. Nature 356: 83-85

31. Braig K, Otwinowski Z, Hegde R, Boisvert DC, Joachimiak A, et al. (1994) The crystal structure of the bacterial chaperonin GroEL at 2.8 A. Nature 371: 578 586.

32. Holtje HD, Gerd Folkers (2008) Molecular modeling: basic principles and applications. Weinheim: Wiley-VCH. x, 310.

33. Liu T, Tang GW, Capriotti E (2011) Comparative modeling: the state of the art and protein drug target structure prediction. Comb Chem High Throughput Screen 14: 532-547. 